\title{
Knowledge and practice of sedentary lifestyle among bankers in Abuja, North-Central Ngeria
}

\author{
*Aderibigbe S.A. ${ }^{1}$, Sule G.O. ${ }^{1}$, Olatona F.A. ${ }^{2}$, Goodman O.O. ${ }^{3}$, Sekoni O.O. ${ }^{4}$
}

\begin{abstract}
Objective: Appropriate regular physical activity is a major component in preventing the growing global burden of chronic disease and at least $60 \%$ of the global population fails to achieve the minimum recommendation of 30 minutes moderate intensity physical activity daily. This study was aimed at assessing the knowledge and practice of sedentary lifestyle among bankers in Bwari Area Council, FCT, Abuja in North-Central Nigeria.
\end{abstract}

Methods: This was a descriptive cross sectional study using self administered questionnaire. Systematic sampling was used to recruit 257 bankers from the various banks within BAC. The data was analysed using EPI INFO computer software package (version 3.5.3).

Results: More than half 174 (67.7\%) of the respondents were aware of sedentary lifestyle; 104 (59.9\%) had good knowledge of sedentary lifestyle while 55 (31.5\%) had poor knowledge. More than half 155 $(60.3 \%)$ of the respondents were sedentary while only $102(39.7 \%)$ were physically active. Knowledge of sedentary lifestyle did not significantly influence practice of sedentary lifestyle.

Conclusion: There was good knowledge of sedentary lifestyle among the respondents. More than half of the bankers were found to be sedentary and about a third were physically active. Programmes aimed at improving physical activity among employees of this occupation group are therefore advocated.

Key words: Sedentary Lifestyle, Knowledge, Practice, Abuja, Global Physical Activity Questionnaire (GPAQ)

*Corresponding Author: DrAderibigbe S.A.; Email: tayonov23@yahoo.com

${ }^{1}$ Department of Epidemiology and Community Health, University of Ilorin, Ilorin, Nigeria

${ }^{2}$ Department of Community Health \& Primary Care, University of Lagos, Lagos, Nigeria

${ }^{3}$ Department of Community Health \& Primary Health Care' College of Medicine, University of Ibadan, Ibadan, Nigeria

${ }^{4}$ Department of Preventive Medicine and Primary Care, College of Medicine, University of Ibadan' Ibadan, Nigeria

Research Journal of Health Sciences subscribed to terms and conditions of Open Access publication. Articles are distributed under the terms of Creative Commons Licence (CC BY-NC-ND 4.0). (http://creativecommons.org/licences/by-nc-nd/4.0).

http://dx.doi.org/10.4314/rejhs.v5i3.6 


\title{
Connaissance et pratique du mode de vie sédentaire chez les banquiers à Abuja, au nord et au centre de la Nigéria
}

\author{
*Aderibigbe S.A. ${ }^{1}$, Sule G.O. ${ }^{1}$, Olatona F.A. ${ }^{2}$, Goodman O.O. ${ }^{3}$, Sekoni O.O. ${ }^{4}$
}

\section{Resume}

Objective: Une activité physique régulière et appropriée est un élément majeur dans la prévention du fardeau mondial croissant des maladies chroniques et au moins $60 \%$ de la population mondiale n'atteint pas la recommandation minimale de 30 minutes d'activité physique d'intensité modérée par jour. Cette étude visait à évaluer la connaissance et la pratique du mode de vie sédentaire parmi les banquiers au Conseil régional de Bwari, FCT, Abuja dans le centre-nord du Nigeria.

Méthode: Il s'agissait d'une étude transversale descriptive utilisant un questionnaire auto-administré. Un échantillonnage systématique a été utilisé pour recruter 257 banquiers des différentes banques au sein de BAC. Les données ont été analysées à l'aide du progiciel informatique EPI INFO (version 3.5.3).

Résultats: Plus de la moitié 174 (67,7\%) des répondants étaient conscients du mode de vie sédentaire; 104 $(59,9 \%)$ avaient une bonne connaissance du mode de vie sédentaire, tandis que $55(31,5 \%)$ avaient de faibles connaissances. Plus de la moitié des répondants $(60,3 \%)$ étaient sédentaires, tandis que seulement $102(39,7 \%)$ étaient actifs physiquement. La connaissance du mode de vie sédentaire n'a pas influencé de manière significative la pratique du mode de vie sédentaire.

Conclusion: Les répondants avaient une bonne connaissance du mode de vie sédentaire. Plus de la moitié des banquiers étaient sédentaires et environ un tiers étaient physiquement actifs. Des programmes visant à améliorer l'activité physique chez les employés de ce groupe professionnel sont donc préconisés.

Mots-clés: Mode de vie sédentaire, Connaissance, Pratique, Abuja, Questionnaire global sur l'activité physique (GPAQ)

Auteur correspondant: Dr Aderibigbe S.A.; Email: tayonov23@yahoo.com

${ }^{1}$ Department of Epidemiology and Community Health, University of Ilorin, Ilorin, Nigeria

${ }^{2}$ Department of Community Health \& Primary Care, University of Lagos, Lagos, Nigeria

${ }^{3}$ Department of Community Health \& Primary Health Care' College of Medicine, University of Ibadan, Ibadan, Nigeria

${ }^{4}$ Department of Preventive Medicine and Primary Care, College of Medicine, University of Ibadan' Ibadan, Nigeria

Research Journal of Health Sciences subscribed to terms and conditions of Open Access publication. Articles are distributed under the terms of Creative Commons Licence (CC BY-NC-ND 4.0). (http://creativecommons.org/licences/by-nc-nd/4.0).

http://dx.doi.org/10.4314/rejhs.v5i3.6 


\section{INTRODUCTION}

Physical inactivity has been related to all causes of mortality, lower quality of life, and to a higher risk of obesity, diabetes, hypertension, coronary heart disease, osteoporosis, fractures, colon cancer, breast cancer, prostate cancer, psychiatric disorders, and an overall higher risk of hospitalization $(1,2)$. Sedentary lifestyle is a term used to denote a type of lifestyle with no or inadequate participation in moderate to vigorous physical activity (3). It is a lifestyle that involves no participation in physical activity and longer time span of sitting down (4). Sedentary behaviour refers to activities that do not increase energy expenditure substantially above the resting level (5). Sedentary activities include sitting, reading, watching television and using computer for most part of the day with little or no vigorous physical exercise (3). Among unhealthy lifestyle, smoking and lack of regular physical activity are of major importance in public health because they are highly prevalent and potentially modifiable (1).

The World Health Organization (WHO) reported a strong relationship between mortality rates and lifestyle practices. WHO further highlighted conditions that promote unhealthy lifestyle practices such as lack of adequate health knowledge, acquisition of misinformation about health matters and development of hazardous lifestyle. One of such lifestyle is physical inactivity or sedentary lifestyle (4). The World Health Organization rates inadequate physical activity as one of the three major threats to health alongside cigarette smoking and poor nutrition $(1,6)$. Physical inactivity is estimated to cause 1.9 million deaths and 19 million disability adjusted life years globally (7). Appropriate regular physical activity is a major component in preventing the growing global burden of chronic disease and at least $60 \%$ of the global population fails to achieve the minimum recommendation of 30 minutes moderate intensity physical activity daily (7).

A study among bank employees in India showed that $16 \%$ of the study subjects had poor knowledge regarding risk factors for coronary heart disease one of which is sedentary lifestyle while $44 \%$ were sedentary in lifestyle (8). Similarly in another study conducted among bankers in Ilorin, 23.3\% had poor knowledge of sedentary lifestyle while $29.6 \%$ were sedentary (9).

Higher levels of sedentary lifestyle prevalence exist in Europe with highest levels in the Mediterranean Countries - Portugal (87.8\%), Belgium (71.7\%). Furthermore, 25 percent of adults in the United States do not engage in any leisure time physical activity, while 34 percent of the population older than fifty years live a sedentary lifestyle (10). Sedentary behavior and level of physical activity of 425 university population in Flores, Argentina was studied using the self reporting global physical activity questionnaire (GPAQ): $31 \%$ were found to be sedentary (5). A cross sectional study conducted in South-west Nigeria among health care workers, revealed that only $20.8 \%$ of the respondents had adequate physical activity level (11).

Banking as a profession is characterised by sitting for most of the day and is therefore a sedentary occupation. Appropriate knowledge of bankers about sedentary lifestyle and how this knowledge can be applied in adopting physically active lifestyle to reduce the health implications of a sedentary lifestyle is considered to be therefore important. This research was conducted to assess the knowledge and practice of bankers towards sedentary lifestyle. It is hoped that this will help to awaken their consciousness about the dangers inherent in a sedentary lifestyle and the need to be physically active.

\section{MATERIALS AND METHODS}

Abuja is the capital city of Nigeria. It is located in the centre of Nigeria, within the Federal Capital Territory (FCT). At the 2006 census, the city of Abuja had a population of $1,406,239$ (12). However, with a growth rate of $3.2 \%$ the projected population will be $1,631,237$ (12). The territory is currently made up of six local councils. Bwari Area Council (BAC) is one of the six Area Councils under the FCT. The total population as at 2006 census was 227,216. However, with a growth rate of $3.2 \%$ the projected population will be 263,571 (12). There are a total of 24 banks in BAC with a total population of 1590 .

This was a descriptive cross sectional study. All the 24 banks in BAC were used for the study. Proportional allocation was used to determine the number of bankers to be included in the study from each of the banks, while systematic random sampling was used to select the respondents. Because the number of respondents required from each bank differs, different sampling intervals were calculated and used for each of the banks. The lists of bankers obtained from the banks were ordered 
alphabetically by the researcher before sampling was done. Depending on the sampling interval, simple random sampling was used to pick the first respondent in each of the banks. On the whole, 257 bankers were recruited into the study from the 24 banks. The formula for estimating single proportion for cross sectional studies when population is less than 10,000 was used in calculating the sample size (13) $\left(\mathrm{n}=\mathrm{z}^{2} \mathrm{pq} / \mathrm{d}^{2} \&\right.$ $\mathrm{nf}=\mathrm{n} / 1+(\mathrm{n}) / \mathrm{N})$, with prevalence $=0.296$, being the proportion of bankers that were living a sedentary lifestyle in a previous Nigerian study (9), $\mathrm{z}$ of $1.96, \mathrm{n}=320, \mathrm{~N}=596$, sampling error set at $5 \%$, and $10 \%$ over estimation to accommodate for non response. A sample size of 229 was obtained. Two hundred and fifty seven (257) were however recruited into the study.

Self administered semi-structured questionnaire was used to elicit the respondents' socio-demographic characteristics and knowledge of sedentary lifestyle. The GPAQ developed by the WHO for physical activity surveillance in countries was used to assess physical activity level of the bankers and determine the percentage of bankers that were sedentary. The GPAQ was adopted ahead of others because the validity and reliability of the GPAQ have been studied in people of different nationalities and it allows the analysis of physical activity in a scale of categories (high, moderate or low physical activity level) according to the existing recommendations of physical activity to promote health (14). Omron digital sphygmomanometer which is clinically validated was used to measure the blood pressure of the respondents. SECA manual weighing scale was used to take subjects body weight in $\mathrm{Kg}$ and SECA portable standiometer was used to measure subjects' height in meters. Weight was measured to the nearest $0.1 \mathrm{~kg}$ while height was measured to the nearest $0.1 \mathrm{~cm}$. Weighing scale was standardized by setting it on $0 \mathrm{~kg}$; subjects took off their shoes and any heavy body material before climbing the scale; the subjects stood erect on the scale and the weight reading were taken. Height measurements were taken in standing position without foot wear and head coverings; subject stood erect on the stadiometer with the stadiometer sliding headpiece resting on the scalp. Standardization of research instruments were carried out before commencement of the study and pre-testing was carried out among selected bankers in Abuja municipal area council (AMAC) Abuja.

Knowledge on sedentary lifestyle was scored and graded into good (4-5), fair (2-3) and poor $(0-1)$. The scoring was done based on the researchers' discretion. The GPAQ collects information on physical activity participation in three settings (or domains) as well as sedentary behavior (time spent sitting or reclining at work, at home, getting to and from places, or with friends but do not include time spent sleeping) comprising 16 questions (P1-P16). The domains are: activity at work; travel to and from places; recreational activities. Physical activity was assessed using a categorical indicator- high, moderate and low level of physical activity. Metabolic equivalents (METs) are used for the analysis of GPAQ data. METs were used to express the intensity of physical activities of the bankers. MET is the ratio of a person's working metabolic rate relative to the resting metabolic rate. One MET is defined as the energy cost of sitting quietly, and is equivalent to a caloric consumption of $1 \mathrm{kcal} / \mathrm{kg} /$ hour. Therefore, when calculating a person's overall energy expenditure using GPAQ data, 4 METs were been assigned to the time spent in moderate activities, and 8 METs to the time spent in vigorous activities.

Physical activity was assessed using a categorical indicator; high, moderate and low level of physical activity. The total time spent in physical activity during a typical week, the numbers of days, as well as the intensity of the physical activity were taken into account. Total physical activity in METs-minute/week which is equal to the sum of the total MET minutes of activity computed for each setting were calculated and level of physical activity were categorized based on the following criteria:

High: A person reaching any of the following criteria is classified in this category:

Vigorous intensity activity on at least 3 days achieving a minimum of at least 1,500 METminutes/week; seven or more days of any combination of walking, moderate or vigorous intensity activities achieving a minimum of at least 3,000 MET-minutes per week.

Moderate: A person not meeting the criteria for the "high" category, but meeting any of the following criteria is classified in this category:

Three or more days of vigorous-intensity activity of at least 20 minutes per day; five or more days of moderate intensity activity; walking of at least 30 minutes per day; five or more days of any combination of walking, moderate or vigorous intensity activities achieving a minimum of at 
least 600 MET-minutes per week.

Low: A person not meeting any of the above mentioned criteria falls in this category.

Mean minutes spent in sitting on average per day of the respondents was also determined.

Definition of sedentary as used in this study refer to those who did not participate in any moderate - vigorous physical intensity activities; those who did not participate up to a number of 3 days in any combination of walking, moderate or vigorous intensity activities and who were also below the minimum of 600 MET-minutes per week.

Sedentary lifestyle was assessed using the GPAQ which allows assessment of physical activity participation at work, for transport, recreation and besides with a final item that asks about the time spent sitting on a typical day.

The study proposal was approved by the Ethical Committee of the University of Ilorin Teaching Hospital. The names of the interviewees were not entered on the questionnaires to ensure confidentiality.

All questionnaires were checked for accuracy and completeness to ensure uniform coding. The analysis was done using EPI INFO computer software package (version 3.5.3). ANOVA and t- test was used to compare means of continuous variables while Pearson Chi square $\left(\chi^{2}\right)$ was used to test statistical significance in cross tabulated variables. Level of statistical significance was predetermined at a p-value of $<0.05$.

\section{RESULTS}

A total of 257 respondents between the ages of $22-54$ years participated in this study. The mean age of the respondents was $31.71 \pm$ 6.34 with age range of 20 - 54 years; $150(58.4 \%)$ males and 107 (41.6\%) females. More than half of the respondents, $174(67.7 \%)$ had heard about sedentary lifestyle; 104 (59.9\%) had good knowledge of sedentary lifestyle; $15(8.6 \%)$ had fair knowledge of sedentary lifestyle and 55 $(31.5 \%)$ had poor knowledge of sedentary lifestyle.

Using the GPAQ to assess physical activity level, 102 (39.7\%) bankers were physically active while 155 (60.3\%) bankers were sedentary. Of the 102 bankers who were physically active, $60(23.3 \%)$ had high level of physical activity; $42(16.3 \%)$ had moderate level of physical activity. The mean time in minutes spent in sedentary activities (sitting or reclining) per day for sedentary respondents was $466.66 \pm$
232.68 minutes (Range: $440-491$ ) and $384.75 \pm$ 222.14 (Range: $350-420$ ) minutes for nonsedentary respondents. The time spent in sedentary activities (sitting or reclining) per day between sedentary and non-sedentary individuals was found to be statistically significant $(p<0.05)$.

\section{DISCUSSION}

More than $70 \%$ of the respondents had good knowledge of sedentary lifestyle and similar proportions $(68 \%)$ were also found among bank employees in Ilorin (9). In this study having good knowledge of sedentary lifestyle was not associated with reduced likelihood of being sedentary. Individuals who had fair knowledge of sedentary lifestyle were more sedentary than individuals who had poor knowledge of sedentary lifestyle. These differences were however not statistically significant and in conformity with the other Ilorin study (9).

The prevalence of sedentary lifestyle among the bankers was $60.3 \%$. This is incongruent with the prevalence of sedentary lifestyle among bank employees in Belgaum city (44\%) and among bankers in Ilorin metropolis $(29.6 \%)(8,9)$ its also lower than the prevalence of sedentary lifestyle among health workers in South-west Nigeria (79.2\%) (11). Similar definition of sedentary lifestyle was used in their own study in which sedentary people refer to those who do not engage in regular moderatevigorous physical activity (11).

In another study that assessed sedentary behaviour and level of physical activity using the GPAQ among 425 university students in Argentina (5), it was discovered that $31 \%$ of the population were sedentary, $40 \%$ had high level of physical activity and $29 \%$ were moderately active. The higher prevalence of sedentary lifestyle obtained from this study compared to the Argentinean study could be due to the difference in the occupation of the respondents. The student population had higher physical activity level than the bankers. This is however not surprising considering that physical activity among students is expected to be higher than obtains in bankers who by nature of their work sit at a spot for long hours. The students on the other hand have a conducive environment for physical activity to thrive (15). Delien et al who worked with student population also found out that their respondents were more willing to engage in physical activity because of the conducive environment (15). The sedentary life style of the respondents $(60.3 \%)$ in this study was higher than the prevalence of 
sedentary lifestyle across European Countries (Denmark 33\% (16); Netherland 17.9\% (17); England 17\%(18)) when sedentary people were based on the definition of low energy expenditure: those expending less than 10 percent of their leisure time in activities involving less than four METs. Also in the study of sedentary lifestyle in the European Countries, sedentary people were also classified based on the definition of no participation in physical activity and long time sitting down: those who did not practice any leisure-time physical activity and who were also above the median in the number of hours spent sitting down during leisure time. This finding of high sedentary lifestyle among our respondents portends a grave danger in the control of non-communicable diseases and may eventually adversely affect long-term health status $(2,19)$.

In this study, $39.7 \%$ of the bankers were physically active: $23.4 \%$ had high level of physical activity while $16.3 \%$ had moderate level of physical activity. Proportion of physically active bankers was lower than proportion of active bankers in Belgaum city $(56 \%)$ and Ilorin metropolis $(70.4 \%)(8,9)$.

Time spent in sitting on average per day between sedentary and non-sedentary respondents was significant with a $\mathrm{p}$-value of 0.005 . This implies that bankers who were sedentary spent more time sitting on an average per day than bankers who were not sedentary. Similar report on sedentary behaviour and physical activity in University of Flores showed that a significant proportion of sedentary respondents were simultaneously in the inter-quartile range of $\geq 600$ minutes of time spent sitting per day (5).

\section{CONCLUSION}

This study revealed that nearly two-third of bankers in Bwari area council (BAC) had good knowledge of sedentary lifestyle. More than half of the bankers were found to be sedentary and about a third were physically active. Programmes aimed at improving physical activity among employees of this occupation group are therefore advocated.

Conflict of interests: The authors declare no conflict of interest

\section{REFERENCES}

1 GlobalHealthRisks report full.pdf. http://www.who.int/healthinfo/global_burden disease/GlobalHealthRisks_report_full.pdf (accessed July 27, 2017).
2 de Rezende LFM, Rodrigues Lopes M, ReyLópez JP, Matsudo VKR, Luiz O do C. Sedentary Behavior and Health Outcomes: An Overview of Systematic Reviews. PLOS ONE 2014; 9. DOI:10.1371/journal.pone.0105620.

3 Sedentary lifestyle. Wikipedia. 2016; published o $\mathrm{n} 1 \mathrm{i} \mathrm{n} \mathrm{e} \quad \mathrm{N}$ o v 22. https://en.wikipedia.org/w/index.php?title=Sed entary_lifestyle\&oldid=750917469 (accessed Dec 2, 2016).

4 Shehu R, Abdullahi A, Adekeye D. Sedentary lifestyle and wellness in Kaduna state, Nigeria. $J$ Ethnobiol Ethnomedicine 2010; 4: 15-9.

5 Farinola M, Bazan N. Sedentary Behavior and Physical Activity in University Students: A Pilot Study. Argent J Cardiol 2011; 79. $<$ http://ppct.caicyt.gov.ar/index.php/rac/article/ view/418> (accessed Dec 1, 2016).

6 Collin J. Tobacco control, global health policy and development: towards policy coherence in global governance. Tob Control 2012; 21: 274-80.

7 World Health Organisation. The World Health Report 2002: Reducing Risks, Promoting Healthy Life. World Health Organization, 2002.

8 Shivaramakrishna H, Wantamutte A, Sangolli H, Mallapur M. Risk Factors of Coronary Heart Disease among Bank Employees of Belgaum City - Cross-Sectional Study. Al Ameen J Med Sci 2010; 3: 152-9.

9 Jogunola O, Awoyemi A. Prevalence of Sedentary Lifestyle among Bankers in Ilorin Metropolis. Niger J Med Rehabil 2012; 15: 44-50.

10 Centers for Disease Control and Prevention. The State of Aging and Health in America 2013. 2013.

11 Iwuala SO, Sekoni AO, Olamoyegun MA, Akanbi MA, Sabir AA, Ayankogbe OO. Selfreported physical activity among health care professionals in South-West Nigeria. Niger $J$ Clin Pract 2015; 18: 790.

12 Nigeria Population Commission. Censuses. http://www.population.gov.ng/index.php/censu ses (accessed Dec 2, 2016).

13 Kirkwood B, Sterne J. Essentials of Medical Statistics, 2 edition. Malden, Mass: WileyBlackwell, 2001.

14 Bull FC, Maslin TS, Armstrong T. Global physical activity questionnaire (GPAQ): nine country reliability and validity study. J Phys Act Health 2009; 6: 790-804.

15 Deliens T, Deforche B, Bourdeaudhuij ID, Clarys P. Determinants of physical activity and sedentary behaviour in university students: a qualitative study using focus group discussions. BMC Public Health 2015; 15: 201.

16 Denmark - Physical Activity Factsheet $\mathrm{d}$ e $\mathrm{n} \mathrm{m}$ a r k - f a c t s h e e t_e n . p d f. http://ec.europa.eu/assets/eac/sport/library/fact sheets/denmark-factsheet_en.pdf (accessed July 27, 2017). 
17 NETHERLANDS Physical Activity Factsheet NETHERLANDS-Physical-Activity-

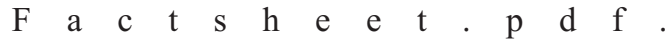
http://www.euro.who.int/_data/assets/pdf_file /0011/288119/NETHERLANDS-PhysicalActivity-Factsheet.pdf?ua=1 (accessed July 27, 2017).

18 Townsend N, Wickramasinghe K, Williams J, Bhatnagar P, Rayner M. Physical Activity Statistics 2015.2015.

19 Bird M-L, Shing C, Mainsbridge C, Cooley D, Pedersen S. Activity Behaviors of University Staff in the Workplace: A Pilot Study. J Phys Act Health 2015; published online Aug 1. DOI:10.1123/jpah.2014-0259 
Table 1: Socio-Demographic Variables of the Respondents $(n=257)$

\begin{tabular}{ll}
\hline Variables & Frequency (\%) \\
\hline Age group (years) & $123(47.9)$ \\
$20-29$ & $105(40.9)$ \\
$30-39$ & $25(9.7)$ \\
$40-49$ & $4(1.6)$ \\
$=50$ & \\
& \\
Gender & $150(58.4)$ \\
Male & $107(41.6)$ \\
Female & \\
Marital Status & \\
Single & $138(53.7)$ \\
Married & $116(45.1)$ \\
Divorced & $2(0.8)$ \\
Widowed & $1(0.4)$ \\
\hline
\end{tabular}

Table 2: Awareness and knowledge of Sedentary Lifestyle $(n=257)$

\begin{tabular}{ll}
\hline Variable & Frequency (\%) \\
\hline Awareness of Sedentary Lifestyle & $174(67.7)$ \\
Aware & $83(32.3)$ \\
Not Aware & \\
Level of knowledge of the respondents & \\
about sedentary lifestyle & $104(59.8)$ \\
Good & $15(8.6)$ \\
Fair & $55(31.6)$ \\
Poor & \\
\hline
\end{tabular}

Table 3: Level of Physical Activity and Distribution of Sedentary Lifestyle among the Bankers ( $\mathrm{n}=257)$

\begin{tabular}{ll}
\hline Variable & Frequency (\%) \\
\hline Level of physical activity & $60(23.4)$ \\
High & $42(16.3)$ \\
Moderate & $155(60.3)$ \\
Low &
\end{tabular}

Distribution Of Sedentary Lifestyle

Sedentary $155(60.3)$

\begin{tabular}{ll} 
Non-sedentary & $102(39.7)$ \\
\hline
\end{tabular}

Table 4: Relationship between level of knowledge and practice of Sedentary Lifestyle among the respondents $(n=257)$

\begin{tabular}{|c|c|c|}
\hline Knowledge grade & Sedentary (\%) & Non-sedentary (\%) \\
\hline Good & $61(58.7)$ & $43(41.3)$ \\
\hline Fair & $11(73.3)$ & $4(26.7)$ \\
\hline Poor & $33(60.0)$ & $22(40.0)$ \\
\hline \multicolumn{3}{|c|}{$\chi^{2}=1.184 ; \mathrm{df}=2 ; \mathrm{p}$-value $=0.553$} \\
\hline
\end{tabular}

Table 5: Comparison of time Spent sitting per day between sedentary and non-sedentary respondents

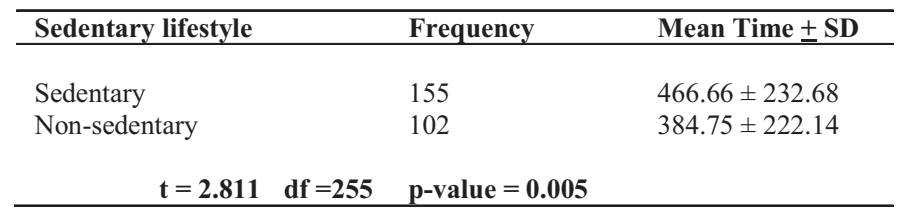

